\title{
Second morning urine method is superior to the casual urine method for estimating daily salt intake in patients with hypertension
}

\author{
Minoru Kawamura, Akihiro Ohmoto, Tomoko Hashimoto, Fukuko Yagami, Masahiko Owada and \\ Takashi Sugawara
}

The accuracy of the casual urine (CU) method for estimating daily salt intake was compared with the second morning urine (SMU) method and with 24-h urine collection (24UC) method as the gold standard. Data were obtained from three previously reported studies, in which we evaluated the daily salt intake by the SMU method. Using SMU samples from 1315 outpatients, the estimated salt intake was lower with the CU method than the SMU method. In inpatients with a daily salt intake of 7, 8 or $18 \mathrm{~g}$, the CU method was applied to SMU specimens. It underestimated salt intake compared with the 24-h collection method whereas the SMU method and 24UC method gave similar results. In the present study, 24UC was done and then urine was collected at $0800,1100,1400,1700$ and 1900 hours, with a daily salt intake of $6 \mathrm{~g}$ in 8 inpatients, $10 \mathrm{~g}$ in 11 inpatients or $15 \mathrm{~g}$ in 5 inpatients. In comparison with the $24 \mathrm{UC}$ method, the $\mathrm{CU}$ method underestimated a high salt intake $(15 \mathrm{~g})$ when morning specimens were used and overestimated a low salt intake $(6 \mathrm{~g})$ when afternoon specimens were used. The correlation between the CU method and 24UC method was weaker $(R=0.57)$ than that between the SMU method and 24UC method $(R=0.85)$. In conclusion, the CU method is heavily influenced by the timing of urine collection and by the actual daily salt intake, so the SMU method provides a better estimate of individual salt intake.

Hypertension Research (2012) 35, 611-616; doi:10.1038/hr.2012.6; published online 2 February 2012

Keywords: antihypertensive drugs; casual urine; circadian rhythm; daily salt intake; second morning urine

\section{INTRODUCTION}

It is known that excessive salt intake influences the risk of cardiovascular diseases such as stroke, ischemic heart disease, heart failure and renal failure, as well as non-cardiovascular diseases such as urolithiasis, osteoporosis, stomach cancer and bronchial asthma. ${ }^{1-3}$ Guidelines for the management of hypertension devised in many countries, ${ }^{4,5}$ including Japan, ${ }^{6}$ recommend the restriction of salt intake to $4-6 \mathrm{~g}$ per day. In $98 \%$ of outpatients from Morioka in the Tohoku District of Japan, daily salt intake was $>6 \mathrm{~g},{ }^{7}$ suggesting that physicians need to provide more appropriate advice about salt restriction. As the first step, evaluation of each patient's daily salt intake is important. Measurement of salt excretion by performing 24-h urine collection (24UC) is the most reliable method of assessing daily salt intake, ${ }^{8,9}$ but it is too inconvenient for general use. ${ }^{10}$ Therefore, many physicians do not assess the daily salt intake of their patients. ${ }^{11}$ Kawasaki et al. ${ }^{10}$ developed a convenient method for monitoring the daily salt intake of healthy persons by using the second morning urine (SMU), which was collected after the first voiding upon awaking, and they called this the SMU method. ${ }^{12}$ Daily salt intake is evaluated by measuring the ratio of sodium to creatinine in the SMU specimen and by calculating daily creatinine excretion as reported previously. ${ }^{13}$ We have found that the accuracy of estimating the daily salt intake by the SMU method is equal to that of the 24UC method if the subject maintains the sitting or standing position until the SMU sample is collected, ${ }^{14}$ and we have also shown that this method was useful in patient on antihypertensive therapy. ${ }^{14,15}$ On the other hand, Tanaka et al. ${ }^{16}$ have developed a simple casual urine (CU) method for public health research. With the $\mathrm{CU}$ method, a urine sample can be collected during the daytime between 0800 hours and 1900 hours, whereas urine is generally collected between 0800 hours and 1000 hours for the SMU method. Also, the equation for predicting daily creatinine excretion is the same for men and women with the CU method, whereas different equations for each sex are needed with the SMU method. The 2009 Guidelines for Management of Hypertension from the Japanese Society of Hypertension adopted the CU method for evaluating daily salt intake at general medical institutions. ${ }^{6}$ At the 2010 Japanese Society of Hypertension meeting, it was reported that $83 \%$ of general physicians followed the Japanese Society of Hypertension Guidelines. ${ }^{17}$ Although physicians who estimate the salt intake of their patients would like to know how reliable the $\mathrm{CU}$ method is and the effect of urine collection time on estimated salt intake, there have been no data available. 
Therefore, we compared the CU and SMU methods for estimating daily salt intake in relation to the $24 \mathrm{UC}$ method as a gold standard.

\section{METHODS}

\section{Subjects}

Data were obtained from three previously reported studies $\left(A,{ }^{18} \mathrm{~B}^{14}\right.$ and $\left.\mathrm{C}^{19}\right)$, in which we evaluated the daily salt intake by the SUM method. In addition, to examine the effects of urine sampling time and actual salt intake on estimation of the daily salt intake by the CU method, we selected 30 hypertensive patients who were admitted to hospital for lifestyle modification and/or to receive treatment for hypertension and/or diabetes mellitus. In the present study, they were assessed at our clinic during a 2-month period before admission, undergoing blood pressure measurement on at least two occasions, and estimation of salt intake by the SMU method with blood and urine tests at least once.

\section{Methods}

Study A was done in 1315 outpatients without restriction of their salt intake. Each subject discarded the first voided urine at awakening, and the second voided urine was collected when they visited hospital (from 0800 to 1000 hours). They did not eat breakfast, did not take any medicines and did not adopt a recumbent posture in the morning before urine collection. Using the SMU sample, daily salt intake was estimated by the CU equation and the SMU equation. In study B, 100 inpatients were given a daily salt intake of $7 \mathrm{~g}$. In study C, 22 inpatients received a daily salt intake of $18 \mathrm{~g}$ for a week, followed by a daily salt intake of $8 \mathrm{~g}$ for another week. Study C was performed in 1994-1995 at Iwate Medical University to which the authors MK and MO belonged. The daily salt intake was estimated as the amount of salt added to food for seasoning. A the salt content of the meals was approximately $1 \mathrm{~g}$, the actual daily salt intake in study $\mathrm{C}$ was approximately 8 and $18 \mathrm{~g}$, although it was reported to be 7 and $17 \mathrm{~g}$. In both studies, daily salt intake was estimated by the 24UC method. The SMU was also collected at 0800 hours, before breakfast and morning medications, and the daily salt intake was estimated by the equations for the $\mathrm{CU}$ and SMU methods. In the present study, the daily salt intake of the patients after admission was set below that estimated by the SMU method before admission, and the same intake was continued after discharge from hospital. In brief, daily salt intake was set at one of the three levels $(6,10$ or $15 \mathrm{~g}$ per day) during admission. The salt content of breakfast, lunch and dinner was adjusted to be similar. Thus, the salt content of breakfast, lunch and dinner over the 7 days of the study was $35 \pm 6 \%, 31 \pm 4 \%$ and $33 \pm 4 \%$ in the $6 \mathrm{~g}$ group, $33 \pm 3 \%, 33 \pm 2 \%$ and $34 \pm 3 \%$ in the $10 \mathrm{~g}$ group, and $32 \pm 4 \%, 34 \pm 3 \%$ and $34 \pm 3 \%$ in the $15 \mathrm{~g}$ group, respectively. Daily calorie intake was set at one of five levels from 1200 to $2000 \mathrm{kcal}$ (at intervals of $200 \mathrm{kcal}$ ) according to the following equation: $25-30 \times$ ideal body weight $\left(22 \times\right.$ height $\left.(\mathrm{m})^{2}\right)$. Calories were principally adjusted by changing the amount of rice in the meals. Daily intake of potassium, calcium and magnesium was not adjusted to remain constant among the three salt intake groups. While in hospital, each patient was required to get up at 0600 hours, eat meals at 0800,1200 and 1800 hours, and go to bed at 2100 hours. By 1 week after admission, it was considered that equilibration of the sodium balance had been achieved, ${ }^{20}$ so urine was collected for 2 days by the following procedure. On Day 1, after voiding at 0600 hours, urine was collected for $24 \mathrm{~h}$, until urine voiding at 0600 hours on the next day. On Day 2, urine was collected at 0800, 1100, 1400, 1700 and 1900 hours. Between 0600 and 0800 hours, the patients were ordered to not to adopt the recumbent position. After 0800 hours, there was no restriction on posture, and voided urine was discarded except at the specified times. Using the 24-h urine sample, salt intake was estimated by the 24UC method. In addition, using the urine samples voided at the specified times, salt intake was estimated by the $\mathrm{CU}$ equation. Furthermore, salt intake was estimated by both the $\mathrm{CU}$ and SMU equations using the urine sample obtained at 0800 hours.

Approval for this study was granted by the ethics committee of Iwate Prefectural Central Hospital. All subjects were given detailed information about the protocol before enrollment and written consent was obtained from all of them.

\section{Table 1 Equations for estimating daily salt intake}

(a) Second morning urine (SMU) method

Estimated daily salt intake ( $\mathrm{g}$ per day) $=0.96 \times(\mathrm{UNa} / \mathrm{UCr} / 10 \times \text { predicted } \mathrm{CrV})^{0.5}$

Male predicted $\mathrm{CrV}$ (mg per day) $=15.12 \times$ body weight $(\mathrm{kg})+7.39 \times$

height $(\mathrm{cm})-12.63 \times$ age (years) -79.90

Female predicted $\mathrm{CrV}(\mathrm{mg}$ per day) $=8.58 \times$ body weight $(\mathrm{kg})+5.09 \times$

height $(\mathrm{cm})-4.72 \times$ age (years) -74.95

\section{(b) Casual urine (CU) method}

Estimated daily salt intake (g per day) $=1.29 \times(\mathrm{UNa} / \mathrm{UCr} / 10 \times \text { predicted } \mathrm{CrV})^{0.392}$ Predicted CrV (mg per day) $=14.89 \times$ body weight $(\mathrm{kg})+16.14 \times$

height $(\mathrm{cm})-2.04 \times$ age (years) -2244.45

Abbreviations: Predicted UcrV, predicted daily creatinine excretion (mg per day); Ucr, urinary creatinine concentration $\left(\mathrm{mg} \mathrm{dl}^{-1}\right)$; UNa, urinary sodium concentration $\left(\mathrm{mEq} \mathrm{I}^{-1}\right)$. SMU equation from reference 10 and CU equation from reference 16 .

\section{Measurements and calculations}

Daily salt intake was calculated by the equations of the CU method ${ }^{16}$ and SMU method, ${ }^{10}$ which are shown in Table 1 . Daily salt intake and daily excretion of creatinine were also determined from the 24 -h urine specimens. Because $90 \%$ of dietary sodium intake is excreted in the urine, ${ }^{21}$ daily sodium excretion is considered to be a surrogate for daily salt intake. Daily sodium intake was expressed as grams of sodium chloride $(\mathrm{NaCl})$, as suggested by the Japanese guideline. ${ }^{6}$ The percent increase of the salt intake estimated by the CU method from morning to afternoon was calculated as follows: $100 \times$ (the average of the estimated salt intakes at 1400,1700 and 1900 hours) $\div$ (the average of the estimated salt intakes at 0800 and 1100 hours).

The urinary albumin concentration was measured by SRL Laboratories (Tokyo), using part of each urine specimen. Hypertension, diabetes and dyslipidemia were defined according to the Japanese Guidelines for Hypertension, ${ }^{6}$ the Diabetes Society ${ }^{22}$ and the Atherosclerosis Society, ${ }^{23}$ respectively. Blood pressure was determined as the mean of the values measured at the last two clinical appointments. Subjects who were using antihypertensive drugs were classified as having hypertension irrespective of their actual blood pressure. When creatinine excretion exceeded $\pm 30 \%$ of the predicted excretion, patients were considered to have performed incorrect urine collection. ${ }^{24}$ Five patients had a creatinine excretion that was $\geqslant 30 \%$ below the predicted value, whereas none had an excretion $>30 \%$ above the predicted value. One patient could not void urine easily because of prostatic hypertrophy. These 6 patients were excluded and the remaining 24 patients were subjected to further analysis.

\section{Statistics}

Results were expressed as the mean \pm s.d. Differences between groups were analyzed by the Wilcoxon signed-rank test. The difference in the percent increase of the salt intake estimated by the $\mathrm{CU}$ method from morning to afternoon among the three different salt intake groups (6,10 and $15 \mathrm{~g}$ per day) was analyzed by the Kruskal Wallis signed-rank test. Linear regression was performed and correlation coefficients were calculated by the least squares method. In all analyses, a probability $(P)$ value of $<0.05$ was accepted as indicating statistical significance.

\section{RESULTS}

Using SMU samples from 1315 outpatients (study A), the relation between the daily salt intake estimated by the $\mathrm{CU}$ equation and the SMU equation is shown in Figure $1 \mathrm{a}$ for men and Figure $1 \mathrm{~b}$ for women. The regression equation was $y=0.58 x+2.19$ for men, and $y=0.63 x+1.84$ for women. For $y=x$, the value was $5.1 \mathrm{~g}$ in men and $5.0 \mathrm{~g}$ in women. Thus, if the daily salt intake calculated by the SMU equation was $13 \mathrm{~g}$, it would be $9.7 \mathrm{~g}$ per day in men and $10.0 \mathrm{~g}$ in women by the CU equation. If the daily salt intake calculated by the SMU equation was $6 \mathrm{~g}$, however, it would be $5.6 \mathrm{~g}$ per day for either sex by the CU equation. 

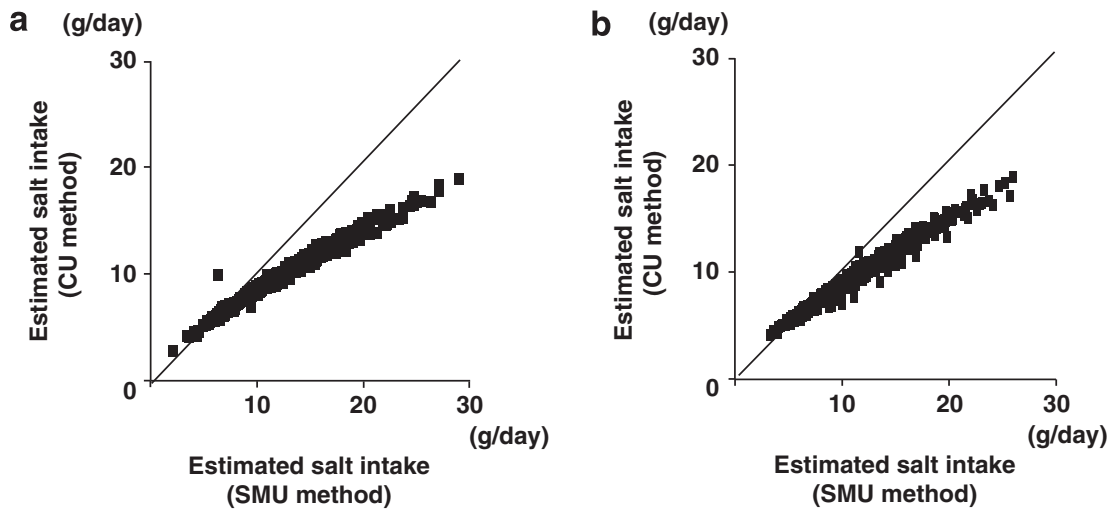

Figure 1 Relation between estimates of daily salt intake by the casual urine (CU) method and the second morning urine (SMU) method using SMU samples from 629 male patients (a) and 686 female patients (b).

Table 2 Influence of the time of urine sampling on estimation of salt intake by the casual urine (CU) method

\begin{tabular}{|c|c|c|c|c|c|}
\hline & \multicolumn{5}{|c|}{ Urine collection time (hours) } \\
\hline & 0800 & 1100 & 1400 & 1700 & 1900 \\
\hline Sodium (mEq $\left.{ }^{-1}\right)$ & $90.4 \pm 54.0$ & $81.5 \pm 49.8$ & $94.1 \pm 64.2$ & $98.9 \pm 68.1$ & $99.3 \pm 75.0$ \\
\hline Creatinine $\left(\mathrm{mg} \mathrm{dl}^{-1}\right)$ & $175.9 \pm 92.1$ & $104.8 \pm 56.8^{*}$ & $69.6 \pm 43.4^{*, \#}$ & $69.4 \pm 46.3^{*, \#}$ & $71.4 \pm 40.7^{*, \#}$ \\
\hline Sodium: creatinine $\left(\mathrm{mEqg}^{-1}\right)$ & $66.6 \pm 50.3$ & $92.1 \pm 58.8^{*}$ & $146.2 \pm 78.6^{*, \#}$ & $160.8 \pm 96.3^{*, \#}$ & $143.2 \pm 69.4^{*, \#}$ \\
\hline Intake (g per day) & $6.7 \pm 2.1$ & $7.7 \pm 2.2^{*}$ & $9.5 \pm 2.2^{*, \#}$ & $9.8 \pm 2.4^{*, \#}$ & $9.6 \pm 1.9^{*, \#}$ \\
\hline
\end{tabular}

${ }^{\star} P<0.05$ compared with 0800 hours by the Wilcoxon signed-rank test. ${ }^{~} \mathrm{P}<0.05$ compared with 1100 hours by the Wilcoxon signed-rank test.

Daily salt intake was estimated by the CU equation or the SMU equation using the SMU sample, and was compared with that estimated by the 24UC method in inpatients who had a daily salt intake of $7 \mathrm{~g}$ in study B, and 8 or $18 \mathrm{~g}$ in study C. As a result, the salt intake estimated by the CU equation, SMU equation and $24 \mathrm{UC}$ method was $5.5 \pm 1.2,6.2 \pm 1.7$ and $6.6 \pm 1.5 \mathrm{~g}$, respectively, when the actual daily salt intake was $7 \mathrm{~g}$ (study B). The salt intake estimated by the CU equation, SMU equation and $24 \mathrm{UC}$ method was $6.5 \pm 1.2$, $8.0 \pm 1.9$ and $7.3 \pm 1.6 \mathrm{~g}$, respectively, when the actual daily salt intake was $8 \mathrm{~g}$ (study $\mathrm{C}$ ), whereas the respective values were $11.3 \pm 1.3$, $16.2 \pm 2.3$ and $15.7 \pm 2.1 \mathrm{~g}$ for an intake of $18 \mathrm{~g}$ (study C). Thus, for a daily salt intake of 7,8 or $18 \mathrm{~g}$, the intake estimated by the $\mathrm{CU}$ equation was significantly lower (all $P<0.05$ ) than that obtained with the 24UC method or the SMU method, whereas no significant difference was observed between the SMU and 24 UC methods.

The 24 subjects ( $13 \mathrm{men}$ ) in the present study had an age of $59 \pm 16$ years, body mass index of $24.6 \pm 5.1 \mathrm{~kg} \mathrm{~m}^{-2}$, systolic blood pressure of $148 \pm 10 \mathrm{~mm} \mathrm{Hg}$ and diastolic blood pressure of $87 \pm 9 \mathrm{~mm} \mathrm{Hg}$. Their hemoglobin $A_{1 c}$ was $7.3 \pm 2.1 \%$, low-density lipoprotein cholesterol was $117 \pm 28 \mathrm{mg} \mathrm{dl}^{-1}$, high-density lipoprotein cholesterol was $59 \pm 22 \mathrm{mg} \mathrm{dl}^{-1}$, triglycerides were $112 \pm 39 \mathrm{mg} \mathrm{dl}^{-1}$, serum creatinine was $0.7 \pm 0.2 \mathrm{mg} \mathrm{dl}^{-1}$ and urinary albumin concentration was $56 \pm 108 \mathrm{mgg}^{-1}$ creatinine. Diabetes mellitus and dyslipidemia were found in $70 \%$ and $50 \%$ of the patients, respectively. In all, 19 patients were taking antihypertensive drugs (one drug in 14 patients and two drugs in 5 patients). A total of 12 patients were using calcium channel blockers (amlodipine, manidipine, cilnidipine, azelnidipine or nifedipine), 11 were taking angiotensin II receptor blockers (candesartan, losartan, olmesartan or valsartan), 5 were prescribed the diuretic hydrochlorothiazide ( $12.5 \mathrm{mg}$ per day), 1 was taking the $\beta$-blocker betaxolol and 1 was using the $\alpha, \beta$ blocker carvedilol. A total of 15 patients were receiving anti-diabetic agents (one drug in 4 , two drugs in 7 and three drugs in 4 patients). In all, 10 patients took metformin, 7 used sitagliptin, 6 received glimepiride, 5 took pioglitazone and 1 each used mitiglinide and miglitol. The daily salt intake was 6, 10 and $15 \mathrm{~g}$ in 8,11 and 5 patients, respectively.

The influence of the urine collection time on estimation by the CU equation is shown in Table 2. The sodium/creatinine ratio of urine collected at 0800 hours was significantly lower than that of urine collected at any other time, and the sodium/creatinine ratio of urine collected at 1100 hours was significantly lower than that of urine collected in the afternoon. Daily salt intake estimated by the CU equation showed a similar pattern to the sodium/creatinine ratio. After stratification of subjects by their daily salt intake $(6,10$ or $15 \mathrm{~g})$, daily salt intake was estimated by the $\mathrm{CU}$ equation using urine samples collected at different times of the day, and the salt intake was compared with the daily salt intake estimated by the 24UC method in subjects with an actual intake of $6 \mathrm{~g}$ (Figure 2a), $10 \mathrm{~g}$ (Figure 2b) and $15 \mathrm{~g}$ (Figure 2c). The daily salt intake estimated by the 24UC method was $4.7 \pm 1.3,7.6 \pm 1.9$ and $12.7 \pm 1.8 \mathrm{~g}$, respectively. When the morning urine sample was employed, the daily salt intake estimated by the $\mathrm{CU}$ equation was approximately $3 \mathrm{~g}$ lower than that obtained by the 24UC method in subjects with an actual salt intake of $15 \mathrm{~g}$ per day, whereas it was not significantly different for the $6 \mathrm{~g}$ per day intake. When the afternoon urine sample was used, the daily salt intake estimated by the CU equation was approximately $3 \mathrm{~g}$ higher than that obtained by the 24UC method in subjects with an intake of $6 \mathrm{~g}$ per day, but was not significantly different with the $15 \mathrm{~g}$ 
per day intake. The percent increase of the salt intake estimated by the CU method from morning to afternoon was $16.3 \pm 4.2 \%$ in the $6 \mathrm{~g}$ per day group, $12.5 \pm 2.2 \%$ in the $10 \mathrm{~g}$ per day group and $13.1 \pm 1.6 \%$ in the $15 \mathrm{~g}$ per day group. There were no significant differences $(P=0.06)$, but the percent increase was higher at $6 \mathrm{~g}$ per day than at 10 or $15 \mathrm{~g}$ per day.

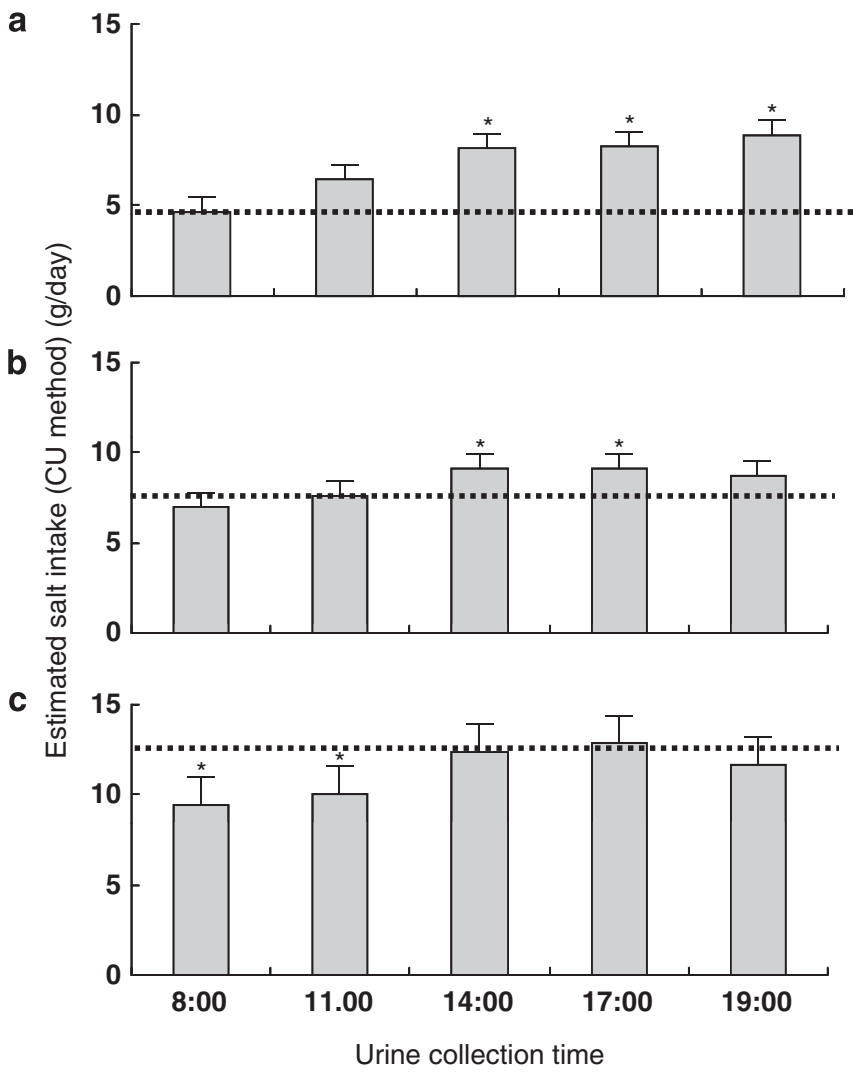

Figure 2 Influence of urine collection time on estimation of daily salt intake by the casual urine (CU) method in subjects with a daily salt intake of $6 \mathrm{~g}$ (a), $10 \mathrm{~g}$ (b) or $15 \mathrm{~g}$ (c). Dotted lines indicate the daily salt intake estimated by the 24 -h urine collection (24UC) method. ${ }^{*} P<0.05$ vs. 24 UC.
A scatter plot of the relation between daily salt intake estimated by the $\mathrm{CU}$ equation (using urine samples collected at various times) and the corresponding salt intake estimated by the 24UC method is shown in Figure 3a. The correlation coefficient was $0.57(P<0.05)$. A scatter plot of the relation between daily salt intake estimated by the CU equation using urine samples obtained at 0800 hours and the corresponding salt intake estimated by the $24 \mathrm{UC}$ method is shown in Figure $3 \mathrm{~b}$. There was a significant positive correlation $(r=0.73$, $P<0.05)$. A scatter plot of the relation between salt intake estimated by the SMU equation using urine samples obtained at 0800 hours and the corresponding salt intake estimated by the 24UC method is shown in Figure $3 c$. There was also a significant positive correlation $(r=0.85$, $P<0.05)$.

\section{DISCUSSION}

Although the CU method theoretically permits urine sampling at any time between 0800 and 1900 hours, we found that the actual daily salt intake was overestimated or underestimated depending on the urine sampling time and the level of salt intake. First, when data on the SMU specimens collected at 0800-1000 hours from outpatients in study A were analyzed, the CU method gave lower estimates than the SMU method if the salt intake was $>5 \mathrm{~g}$ per day, and the difference became larger at higher levels of salt intake. For example, the difference was $3 \mathrm{~g}$ when the SMU method gave a daily intake of $13 \mathrm{~g}$, whereas the difference was only $0.6 \mathrm{~g}$ when the SMU method gave an intake of $6 \mathrm{~g}$. Accordingly, the $\mathrm{CU}$ equation provides markedly different estimates from those of the SMU equation in persons with a high salt intake using urine collected during the morning. We emphasize that this difference was found in a large group of outpatients who had different lifestyles, indicating that choosing between these two equations for estimation of salt intake can have a marked impact in populations with a high salt intake.

Second, the salt intake estimated by the CU and SMU equations with SMU samples were compared with that estimated by the 24UC method using data from studies B and C. When the actual daily salt intake was 7, 8 and $18 \mathrm{~g}$, the $\mathrm{CU}$ equation underestimated the salt intake in comparison with $24 \mathrm{UC}$ method, whereas the salt intake estimated by the SMU equation corresponded with that obtained by the 24UC method. Thus, the CU equation underestimated salt intake when using urine collected during the morning, whereas the SMU
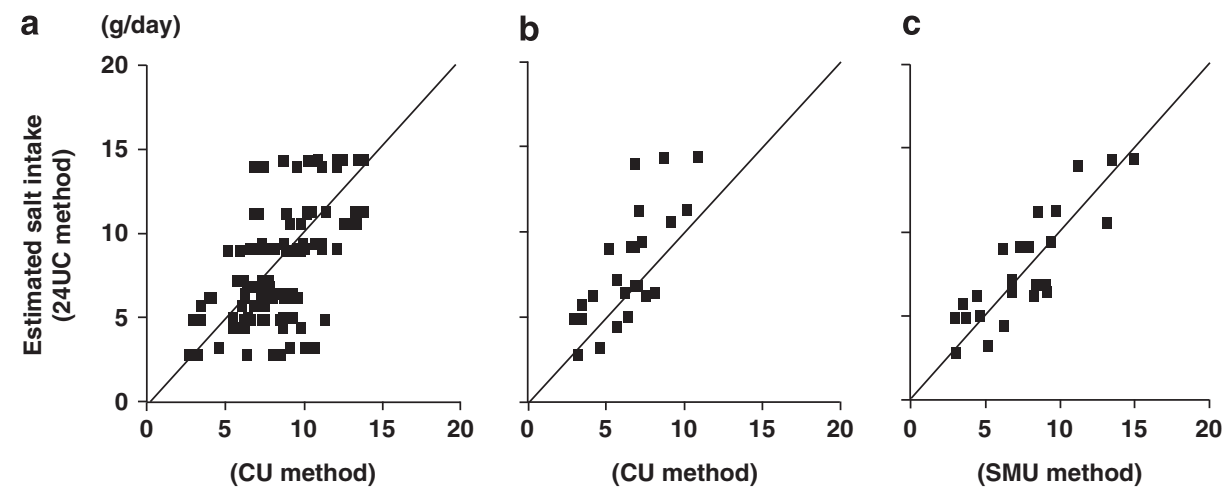

Estimated salt intake (g/day)

Figure 3 Scatter plots of the relations between different estimates of salt intake. (a) Salt intake estimated by the casual urine (CU) method using urine samples collected at different times vs. the corresponding salt intake estimated by the 24-h urine collection (24UC) method. (b) Salt intake estimated by the casual urine (CU) method using urine samples collected at 0800 hours vs. the corresponding salt intake estimated by the $24-\mathrm{h}$ urine collection (24UC) method. (c) Salt intake estimated by the second morning urine (SMU) method using urine collected at 0800 vs. the corresponding salt intake estimated by the 24UC method. The correlation coefficients were $0.57(P<0.05)(\mathbf{a}), 0.73(P<0.05)(\mathbf{b})$ and $0.85(P<0.05)(\mathbf{c})$. 
equation gave accurate results. Third, the present study was performed to examine the influence of urine sampling time and actual salt intake on the CU method. It showed that the salt intake estimated with morning urine by the $\mathrm{CU}$ method was significantly lower than that obtained by the $24 \mathrm{UC}$ method when the actual salt intake was $15 \mathrm{~g}$ per day, so a high salt intake was underestimated by the CU method if urine was collected during the morning. This corresponded to the results obtained from analyzing the data of studies A, B and C. On the other hand, the salt intake estimated by the CU method with afternoon urine was significantly higher than that obtained by the $24 \mathrm{UC}$ method when the actual salt intake was $6 \mathrm{~g}$ per day, suggesting that the salt intake was overestimated by the CU method in persons on a low salt diet. Thus, salt intake was either overestimated or underestimated by the CU method depending on the urine sampling time and the actual salt intake status. Finally, the correlation between salt intake estimated by the CU and by the 24UC method was only 0.57, suggesting that the $\mathrm{CU}$ method is inaccurate for estimation of salt intake in individual patients.

In the present study, the urine collected at 0800 hours was a SMU sample, so the daily salt intake was also estimated from the SMU equation and compared with salt intake estimated by the 24UC method, yielding a correlation coefficient of 0.85 . This was similar to the correlation coefficient of 0.82 obtained by Kawasaki using unrestricted subjects and urine collection for 3 days. ${ }^{10}$ It is evident that the SMU method is superior to the $\mathrm{CU}$ method with regard to estimation of the a daily salt intake. Tanaka et al. ${ }^{16}$ developed the CU method and reported that it is not suitable for estimating individual sodium excretion, but useful for estimating population mean levels of $24 \mathrm{~h}$ sodium excretion.' Because an individual patient's estimated daily salt intake is important in clinical practice, the SMU method should be used for estimation of salt intake.

Why did the urine collection time have a marked influence on estimation of salt intake by the CU equation? With all three levels of salt intake tested, the intake estimated by the $\mathrm{CU}$ equation was lower with morning urine samples than with afternoon samples (Figure 2). This was probably related to the circadian rhythm of urinary sodium excretion, ${ }^{25-28}$ which results in lower excretion during the morning than during the afternoon. As the creatinine excretion rate is almost constant throughout $24 \mathrm{~h},{ }^{29}$ the urinary sodium/ creatinine ratio reflects the circadian rhythm of sodium excretion and the estimated salt intake is lower when a morning urine sample is employed than with an afternoon urine sample. Although the timing of meals may also influence the urinary sodium excretion pattern, Muratani et al. ${ }^{28}$ indicated that other factors are important for setting the circadian rhythm of sodium excretion because it was maintained in patients on total parenteral nutrition. These other factors may include the sympathetic nervous system, the reninangiotensin system and atrial natriuretic peptide, all of which influence sodium handling by the kidneys and have their own circadian rhythms. ${ }^{30,31}$

There are several possible explanations for the finding of a larger percent increase of the salt intake estimated by the CU method from morning to afternoon in the $6 \mathrm{~g}$ per day group compared with the other groups, although it was not statistically significant. First, hydrochlorothiazide may have been responsible for the larger percent increase because four patients used this diuretic in the $6 \mathrm{~g}$ per day group $v s$. one patient in the $10 \mathrm{~g}$ per day group and none in the $15 \mathrm{~g}$ per day group. The peak of natriuresis induced by this diuretic was reported to occur at $6-12 \mathrm{~h}$ after administration, although the study was performed with a high dose $(50 \mathrm{mg}){ }^{32}$ A second possible explanation is the effect of posture, as the difference between a recumbent posture and standing is about twofold sodium excretion. ${ }^{33}$ This is equivalent to $1.3\left(=2^{0.392}\right)$ times the salt intake estimated by $\mathrm{CU}$ method, suggesting that posture has a considerable impact on the estimated intake. As there were no restrictions on posture except from 0600 to 0800 hours, changes of posture may have been responsible for the different percent increases among the three different salt intake groups. The third possibility is that a difference in potassium intake may have altered sodium excretion ${ }^{34}$ because there was no attempt to maintain a constant potassium intake among the three different salt intake groups in the present study. The dietary approach to stop hypertension diet, which has lower amounts of total and saturated fat and cholesterol with larger amounts of potassium, calcium, magnesium, dietary fiber and protein than a typical diet, has been suggested to cause natriuresis judging from the reported pressure-natriuresis relationship. ${ }^{35}$ These food components could also influence sodium excretion. Fourth, it is possible that anti-diabetic agents may have influenced sodium excretion because insulin has been reported to be involved in sodium excretion. ${ }^{36}$ Moreover, calorie restriction was prescribed for the pre-obese and obese patients because their calorie intake was determined on the basis of ideal body weight. However, it is unlikely that mild calorie restriction caused natriuresis, because we previously reported that reduction of calorie intake from $1500-2000 \mathrm{kcal}$ per day to $900 \mathrm{kcal}$ per day did not cause significant natriuresis under a constant salt intake. ${ }^{37}$

There were several limitations of our study. First, the number of subjects was small (24 patients) and there were only 5 patients with a high salt intake ( $15 \mathrm{~g}$ per day). In spite of this small number, we found that the salt intake was underestimated by the CU method (approximately $3 \mathrm{~g}$ too low) in patients with a high salt diet using morning urine samples. This result was supported by our finding a difference of $3 \mathrm{~g}$ for estimation of the salt intake of 1315 outpatients when the SMU method gave an intake of $13 \mathrm{~g}$ in study A. Second, we reported that the posture before collection of the SMU sample was important for correctly estimating daily salt intake by the SMU method. ${ }^{14}$ In studies $\mathrm{A}$ and $\mathrm{B}$, as well as the present study, the subjects did not adopt a recumbent posture before the SMU collection. In study C, however, urine collection was done without any restrictions on posture because we did not recognize the importance of posture at that time (although the patients did not adopt the recumbent position according to their diary records). Third, the present study was performed in patients who wanted to initiate lifestyle modifications with diet and exercise, and they had comparatively mild target organ damage. Thus, it remains unclear whether the present results would be applicable to patients with severe target organ damage and patients with accelerated hypertension, because such patients may have a different circadian rhythm of sodium excretion. ${ }^{38}$

In conclusion, the $\mathrm{CU}$ method was shown to underestimate the daily salt intake of persons with a high salt intake when morning urine samples were employed, and this finding was supported by the analysis of data from our previous studies A, B and C. On the other hand, the CU method overestimated the salt intake of persons with a low salt intake when afternoon urine samples were used. Correlations with the 24UC method were weaker for the CU method $(R=0.57)$ than the SMU method $(R=0.85)$. Because estimation of salt intake by the CU method is influenced by both the urine sampling time and the actual salt intake status, the SMU method should be used to estimate the salt intake of individual patients in daily practice.

\section{ACKNOWLEDGEMENTS}

We thank Dr Terukazu Kawasaki for his valuable advice and Ms Kazumi Yamamoto for her excellent clerical assistance. 
1 Meneton P, Jeunemaitre X, de Wardener HE, MacGregor GA. Links between dietary salt intake, renal salt handling, blood pressure, and cardiovascular diseases. Physiol Rev 2005; 85: 679-715.

2 He FJ, MacGregor GA. A comprehensive review on salt and health and current experience of worldwide salt reduction programmes. J Hum Hypertens 2009; 23 : 363-384.

3 Appel LJ, Frohlich ED, Hall JE, Pearson TA, Sacco RL, Seals DR, Sacks FM, Smith SC, Vafiadis DK, van Horn LV. The importance of population-wide sodium reduction as means to prevent cardiovascular disease and stroke: a call to action from the American Heart Association. Circulation 2011; 123: 1138-1143.

4 Appel LJ, Brands MW, Daniels SR, Karanja N, Elmer PJ, Sacks FM. Dietary approach to prevent and treat hypertension: a scientific statement from the American Heart Association. Hpertension 2006; 47: 296-308.

5 Mancia G, De Backer G, Dominiczak A, Cifkova R, Fagard R, Germano G, Grassi G, Heagarty A, Kjeldsen SE, Laurent S, Narkiewicz K, Boudier HAJS, Zanchetti A. The task force for the management of arterial hypertension of the European Society of Hypertension (ESH) and of the European Society of Cardiology (ESC). 2007 Guidelines for the management of arterial hypertension. J Hypertens 2007; 25: 1105-1187.

6 Ogihara T, Kikuchi K, Matsuoka H, Fujita T, Higaki J, Horiuchi M, Imai Y, Imaizumi T, Ito $\mathrm{S}$, Iwao $\mathrm{H}$, Kario K, Kawano $\mathrm{Y}$, Kim-Mitsuyama S, Kimura G, Matsubara H, Matsuura H, Naruse M, Saito I, Shimada K, Shimamoto K, Suzuki H, Takishita S, Tanahashi N, Tsuchihashi T, Uchiyama M, Umemura S, Ishimitsu T, Rakugi H. The Japanese Society of Hypertension guidelines for the management of hypertension. Hypertens Res 2009; 32: 3-107.

7 Hashimoto T, Yagami F, Owada M, Sugawara T, Kawamura M. Salt preference according to a questionnaire vs. dietary salt intake estimated by a spot urine method in participants at a health check-up center. Intern Med 2008; 47: 399-403.

8 Intersalt Cooperative Research Group. Intersalt: an international study of electrolyte excretion and blood pressure. Results for $24 \mathrm{~h}$ urinary sodium and potassium excretion. BMJ 1988; 297: 319-328.

9 Kawano Y, Tsuchihashi T, Matsuura H, Ando K, Fujita T, Ueshima H. Report of the working group for dietary salt reduction of the Japanese Society of Hypertension: (2) assessment of salt intake in the management of hypertension. Hypertens Res 2007; 30: 887-893.

10 Kawasaki T, Itoh K, Uezono K, Sasaki H. A simple method for estimating $24 \mathrm{~h}$ urinary sodium and potassium excretion from second morning voiding urine specimen in adults. Clin Exp Pharmacol Physiol 1993; 20: 7-14.

11 Etoh T. Results of a self-administered questionnaire for salt restriction program among participant doctors of educational meeting for hypertension. Bull Jpn Soc Hypertens 2006; 30: 8-10 (in Japanese).

12 Kawasaki T, Kawamura M, Ito K. Second morning urine method developed for estimating daily sodium and potassium excretion. J Metab Clin Nutr 2008; 11 . 237-253 (in Japanese).

13 Kawasaki T, Uezono K, Itoh K, Ueno M. Prediction of 24-hour urinary creatinine excretion from age, body weight, and height of an individual and its application. Jpn J Pub Health 1991; 38: 567-574 (in Japanese).

14 Kawamura M, Hashimoto T, Owada M, Sugawara T. The influence of posture on the estimation of daily salt intake by the second morning urine method. Hypertens Res 2010; 33: 505-510.

15 Kawamura M, Kusano Y, Takahashi T, Owada M, Sugawara T. Effectiveness of a spot urine method in evaluating daily salt intake in hypertensive patients taking oral antihypertensive drugs. Hypertens Res 2006; 29: 397-402.

16 Tanaka T, Okamura T, Miura K, Kadowaki T, Ueshima H, Nakagawa H, Hashimoto T. A simple method to estimate populational $24-h$ urinary sodium and potassium excretion using a casual urine specimen. J Hum Hypertens 2002; 16: 97-103.

17 Kai H, Imaizumi T. The digest of the 33rd annual meeting of the Japanese Society of Hypertension. http://medical.nikkeibp.co.jp/leaf/all/gakkai/jsh2010/201010/517094. html. Accessed October 31, 2011 (in Japanese).
18 Hashimoto T, Owada M, Kawamura M, Ogino T. A large-scale survey of daily salt intake among outpatients in the Morioka area. Med J Iwate Pref Hosp 2010; 49: 1025-1026 (in Japanese).

19 Hashimoto T, Owada M, Sugawara T, Kawamura M. The estimated salt intake by Kawasaki's method in response to a change in salt intake in patients with hypertension. J Blood Pressure 2007; 14: 83-84 (in Japanese).

20 Kawasaki T, Delea CS, Bartter FC, Smith H. The effect of high-sodium and low-sodium intakes on blood pressure and other related variables in human subjects with idiopathic hypertension. Am J Med 1978; 64: 193-198.

21 Holbrook JT, Patterson KY, Bodner JE, Douglas LW, Veillon C, Kelsay JL, Mertz W, Smith $\mathrm{Jr} \mathrm{JC}$. Sodium and potassium intake and balance in adults consuming self-selected diets. Am J Clin Nutr 1984; 40: 786-793.

22 Kuzuya K, Nakagawa S, Satoh J, Kanazawa T, Iwamoto Y, Kobayashi M, Nanjo K, Sasaki A, Seino Y, Ito C, Shima K, Nonaka K, Kadowaki T. Report of the Committee of Japan Diabetes Society on the classification and diagnostic criteria of diabetes mellitus. J Japan Diabetes Soc 1999; 42: 385-404 (in Japanese).

23 Japan Atherosclerosis Society. Japan Atherosclerosis Society Guidelines for Prevention of Atherosclerotic Cardiovascular Diseases. Kyowa Kikaku: Tokyo, 2007, pp 11-13 (in Japanese).

24 Hashimoto T, Yagami F, Owada M, Sugawara T, Kawamura M. Application of a formula to predict 24-h urinary excretion of creatinine in obese patients. Med J Iwate Pref Hosp 2008; 48: 14-18 (in Japanese).

25 Wesson LG, Lauler DP. Diurnal cycle of glomerular filtration rate and sodium and chloride excretion during response to altered salt and water balance in man. J Clin Invest 1961; 40: 1967-1977.

26 Kawasaki T, Nakamuta S, Fukiyama K, Omae T. Determination of urinary excretions of aldosterone and sodium by short term collections of urine in healthy men. Jpn Circ $J$ 1979; 43: 621-626.

27 Kawasaki T, Uezono K, Omae T, Haus E, Halberg F. Comparison of circadian rhythms of renin-angiotensin-aldosterone system and electrolytes in clinically healthy young women in Fukuoka (Japan) and Minnesota (USA). Acta Endocrinologica 1983; 102: 246-251.

28 Muratani H, Kawasaki T, Ueno M, Kawazoe N, Fujishima M. Circadian rhythms of urinary excretions of water and electrolytes in patients receiving total parental nutrition (TPN). Life Sciences 1985; 37: 645-649.

29 Kawasaki T, Uezono K, Ueno M, Kikkawa K, Komuro T, Nakamuta S, Kawazoe N, Mratani $H$, Omae T. Studies of urinary creatinine excretion in clinically healthy subjects: influence of age, sex, exrcise and amount of salt intake on urinary creatinine excretion and its circadian rhythm. J Health Sci 1984; 6: 1-8 (in Japanese).

30 Portaluppi F, Bagni B, Uberti E, Montanari L, Cavallini R, Trasforini G, Margutti A, Ferlini M, Zanella M, Parti M. Circadian rhythms of atrial natriuretic peptide, renin, aldosterone, cortisol, blood pressure and heart rate in normal and hypertensive subjects. J Hypertens 1990; 8: 85-95.

31 Schoefl C, Becker C, Prank K, Muhlen A, Brabant G. Twenty-four-hour rhythms of plasma catecholamines and their relation to cardiovascular parameters in healthy young men. Eur J Endocrinol 1997; 137: 675-683.

32 Ford RV. The clinical pharmacology of hydrochlorothiazide. South Med J 1959; 52: 40-45.

33 Adachi T, Kawamura M, Owada M, Hiramori K. Effect of age on renal functional and orthostatic vascular response in healthy men. Clin Exp Pharmacol Physiol 2000; 28: 877-880.

34 Fujita T, Ando K. Hemodynamic and endocrine changes associated with supplementation in sodium-loaded hypertensives. Hypertension 1984; 6: 184-192.

35 Akita S, Frank FM, Sacks LP, Conlin PR, Kimura G. Effects of the dietary approaches to stop hypertension (DASH) diet on the pressure-natriuresis relationship. Hypertension 2003; 42: 8-13

36 DeFrenzo RA. The effect of insulin on renal sodium metabolism. Diabetologia 1981; 21: 165-171.

37 Kawamura M, Kojima S, Akasaka T, Kasatsuki T, Hiramori K, Ito K, Omae T. Effect of a hypocaloric diet on blood pressure and sodium balance in overweight patients with essential hypertension. Hypertens Res 1992; 15: 137-142.

38 Kimura G, Dohi Y, Fukuda M. Salt sensitivity and circadian rhythm of blood pressure: the keys to connect CKD with cardiovascular events. Hypertens Res 2010; 33: 515-520. 